\title{
DO "HABITUS LINGUÍSTICO" E SEU PAPEL NA PRÁTICA DA PESQUISA CIENTÍFICA
}

Samir Adamoglu de Oliveira ${ }^{1}$

$\mathrm{Na}$ contribuição que ofereço, a noção bourdieusiana de habitus científico, que nesta Mesa vem sendo analisada como prática, o modus operandi do pesquisador, passa a ser agora encarada como práticas linguísticas e, seguindo o mesmo autor, se tentará ver os aspectos políticos que elas de fato têm na comunidade científica. Deixamos, portanto, uma clivagem do habitus no método, foco das participações anteriores, para passar a considerar o conjunto do ofício científico, inclusive em sua dimensão social-corporativa.

Se uma reflexão sobre o que são práticas de pesquisa politizadas tiver de ser levada a efeito, então, importa discutir de que maneira os usos da linguagem por parte de comunidades de pesquisadores são um componente fundamental da própria constituição delineadora do que se aceita por teoria e método científico. Tentarei esclarecer esse ponto, ao longo da minha fala.

Como todo campo social, o campo científico também se configura como um campo constituído por uma estrutura de relações objetivas, por posições sustentadas pelos seus integrantes, e por algum tipo de capital que imbui estes integrantes e suas ações na configuração do próprio campo. Em sua obra "Os Usos Sociais da Ciência", Bourdieu (2004) nos apresenta um tipo de capital simbólico próprio a este campo, o capital científico, que se funda a partir de dois elementos: (i) atos de conhecimento e reconhecimento dentre pares-concorrentes de uma comunidade (envolvendo, por exemplo, questões de prestígio e estima pessoais, ou ainda, crédito intelectual); e, também a partir (ii) de um poder político institucional ou institucionalizado que remete à ocupação de posições importantes nas hierarquias das instituições científicas de ensino e pesquisa, o qual se distribui pelos meios de produção e de reprodução dessas hierarquias.

É esse capital científico que define, em boa margem, o conjunto de objetos relevantes e que interessam, em um dado tempo e espaço, as

\footnotetext{
${ }^{1}$ Professor Adjunto do Departamento de Administração da Universidade Federal da Paraíba (DADM-UFPB). Docente Permanente do Programa de Pós-Graduação em Administração da Universidade Federal da Paraíba (PPGA-UFPB). Pesquisador Associado do Instituto Brasileiro de Estudos e Pesquisas Sociais (IBEPES). E-Mail: samiroliveira09@hotmail.com..
}

Revista Brasileira de Estudos Organizacionais · v. 3. n. 2, p. 210-215, dez.2016, eISSN: 2447-4851 Doi 10.21583/2447-4851.rbeo.2016.v3n2.88 Sociedade Brasileira de Estudos Organizacionais 
questões dominantes e paradigmáticas de um campo científico, condicionando, por vezes, o conjunto de questões legítimas sobre as quais os pesquisadores concentrarão seus esforços de pesquisa e estudo, dentro das comunidades nas quais transitam (BOURDIEU, 2004). E, nesse processo, a linguagem desempenha um papel fundamental, diante do que se pode associar com a retórica científica, da qual fala Roy Harris (2005), quando este nos informa que não há divórcio entre a ciência e a linguagem empregada na sua constituição, já que a plausibilidade das afirmações científicas depende da plausibilidade da linguagem com a qual aquelas são articuladas.

As disposições incorporadas de conhecimentos adquiridos que Bourdieu (2004) sintetiza em sua noção de habitus são fundamentalmente dependentes da estrutura de linguagem na qual falantes e ouvintes de uma comunidade linguística são socializados, e dos modos de uso da linguagem pelos quais os mesmos falantes e ouvintes de uma comunidade linguística agem, interagem, transitam, e sustentam relações, numa base cotidiana. Em "A Economia das Trocas Linguísticas", Bourdieu (1996) versa sua teoria da prática à linguagem, argumentando que as regularidades de uso da linguagem não se explicam apenas mediante o conhecimento de códigos ou de regras, mas principalmente a partir de tais "disposições e esquemas incorporados, os quais não são seguidos ou obedecidos, mas atualizados no discurso" (HANKS, 2008, p. 42), de maneira que "a produção da fala e do discurso são formas de ocupar posições em campos sociais, de forma que os falantes passam a ter trajetórias em cujo percurso eles perseguem diversos valores" (HANKS, 2008, 44). Conforme argumenta Bourdieu (1996, p. 32; 33):

[...] a língua é um código, no sentido de cifra que permite estabelecer equivalências entre sons e sentidos, mas também na acepção de sistema de normas que regem as práticas linguísticas. [...] Enquanto produto da dominação política incessantemente reproduzida por instituições capazes de impor o reconhecimento universal da língua dominante, a integração numa mesma 'comunidade linguística' constitui a condição da instauração de relações de dominação linguística. [...] as 'línguas' só existem em estado prático, ou seja, sob a forma de habitus linguísticos pelo menos parcialmente orquestrados e de produções orais desses habitus.

Desse modo, enquanto disposições adquiridas na formação social dos falantes e ouvintes, o habitus linguístico corresponde às disposições para determinados tipos de usos da linguagem, os quais são socialmente avaliados com base em condições de expressão articulada de ideias, opiniões, convicções, trejeitos, maneirismos, gestos, posturas, corporalidade e competências comunicativas de diversas sortes (oratória, 
eloquência, vocalizações, impostações, etc.), presentes na produção da fala e da audição dos praticantes (HANKS, 2008). Contudo, sempre devoto à importância da dimensão social estruturante e estruturada que marca sua obra, Bourdieu (1996) não desconsidera a importância do componente institucional na compreensão do seu habitus linguístico. Pelo contrário: "o uso da linguagem, ou melhor, tanto a maneira como a matéria do discurso, depende da posição social do locutor que, por sua vez, comanda o acesso que se lhe abre à língua da instituição, à palavra oficial, ortodoxa, legítima" (BOURDIEU, 1996, p. 87).

Esse contraponto externalista ao que aparentaria ser uma leitura estritamente internalista do uso da linguagem se faz crucial, pois, ainda que dependente de atos performativos, a autoridade de que se reveste a linguagem vem de fora, viabilizando os efeitos ilocucionários e perlocucionários da própria fala. Isso significa dizer que, embora as condições de enunciar algo sejam possíveis para diversos pesquisadores em diferentes comunidades científicas, as condições de todos serem ouvidos, produzirem impactos e terem seus trabalhos reconhecidos em termos das contribuições ofertadas, por sua vez, não o são. Depreendemos essa restrição a partir do que explica Bourdieu (1996; 2004), pois, sendo a detenção de capital científico algo variável, então, as próprias condições de reconhecimento, visibilidade, apropriação e uso dos achados comunicados tendem a ser mais restritas, diante da própria distribuição do capital científico, nesse campo social. Envolve, assim, a distribuição dos agentes em posições-práticas centrais ou periféricas, no campo.

Exemplifica-se isso em circunstâncias nas quais pesquisadores podem alcançar achados ou conclusões bastante similares em projetos de pesquisa distintos, mas, a ressonância de quem os enuncia marca, diferentemente, a associação que os pares-concorrentes de uma comunidade científica fazem acerca de quem disse o que primeiro, mediante qual respaldo de legitimidade teórico-metodológica, e mesmo de instituição a qual pertence, amparando o resultado comunicado - algo já explicado por Merton (1996), ainda que sob outros contornos de argumento. Por isso:

[...] todos os esforços para encontrar na lógica propriamente linguística das diferentes formas de argumentação, de retórica e de estilística, o princípio de sua eficácia simbólica, estão condenados ao fracasso quando não logram estabelecer a relação entre as propriedades do discurso, as propriedades daquele que o pronuncia e as propriedades da instituição que o autoriza a pronunciá-lo (BOURDIEU, 1996, p. 89).

"Onde a linguística vê apenas competências e interações comunicativas, é preciso reconhecer capital linguístico e bens linguísticos, 
avaliados em mercados linguísticos", segundo leis que regem esse mercado, "[...] as quais permitem aos detentores de capital linguístico concretizar vantagens simbólicas no âmbito do reconhecimento", nos esclarece Pierre Encrevé (2005, p. 266). Essas vantagens simbólicas interessam de modo a colocarmos, em perspectiva, a análise do campo social científico, do contrário, tanto a leitura linguística que habilita o entendimento sobre a formação desses mercados, quanto a leitura sobre as dinâmicas relacionais (em termos de o que os seus detentores transacionam) correm o risco de serem estabelecidas de modo ingênuo, onde se ignorem os capitais e as posições-práticas dos atores/grupos analisados, naturalizando-o (o campo social científico, sua formação, e a concretização de vantagens simbólicas nele presentes) como algo desprovido de intenções ou de interesses, por parte dos agentes.

Se o ato de praticar competentemente uma linguagem - no caso do jargão científico, um 'idioma' cada vez mais instrumentalizado, como nos fala Habermas (2014) - também depende da posição do seu praticante, de modo a este conseguir produzir efeitos institucionais, então, os mecanismos sociais e políticos de legitimação e dominação - não apenas acerca daquilo que se pode (ou deve-se) enunciar, mas, principalmente, dos modos de enunciá-lo - parece-me configurar um aspecto crucial dessa primordialidade do habitus ante o método, ao qual esta Mesa se destina a enfocar. É possível afirmar isso, pois, os modos de uso da linguagem por parte de comunidades de pesquisadores dotados de capital científico expressivo produzem efeitos técnicos e políticos. Esses efeitos se concretizam a partir de atos de concordância, endosso, rechaço, ou depreciação para com diversos temas, abordagens, objetos, conceitos, teorias, métodos, bem como pelo próprio ato de se valorizar e priorizar determinados problemas que mobilizam a produção de pesquisa, em uma comunidade científica.

Em boa medida, é esse o processo por trás da "illusio" da qual fala Bourdieu (2004, p. 30), e que representa aquele "[...] interesse desinteressado e interesse pelo desinteresse" da ciência que acaba por especificar qual "[...] jogo científico merece ser jogado", qual "[...] vale a pena", e que "[...] define os objetos dignos de interesse, interessantes, importantes, capazes, portanto de merecer o investimento" de uma pesquisa científica - ponto que me parece remeter ao que o Prof. Márcio, expressou há pouco, em seu texto. Enquanto um espaço que se pretende plural como a comunidade interdisciplinar para a qual esta Mesa se dirige, a noção de habitus parece, sim, potencializar a reflexão sobre as 'ações estratégicas localizadas' da prática dos pesquisadores que dela participam. Contudo, é preciso problematiza-la do ponto de vista das posiçõespráticas onde estes mesmos pesquisadores se encontram no campo, e das comunidades nas quais transitam, de modo a não ignorarmos as 
circunstâncias - mais ou menos habilitadoras, mais ou menos restritoras de inserção, participação e enunciação das suas próprias produções.

Também desejo remeter-me ao "efeito desobstrutivo da concepção metodológica de habitus", do qual nos falou o Prof. Pedro, em sua leitura. Parece-me importante que, para acompanhar essa reflexão que visa uma saída do pesquisador daquele conforto ilusório do método, pensemos sobre as tradições nas quais ele foi introduzido, ao longo da sua própria trajetória de estudos, de participação em grupos e projetos de pesquisa, e de reprodução paulatina das práticas de pesquisa sustentadas e legitimadas nas comunidades científicas nas quais transita. Por serem essas atividades centrais no processo de aculturação nas regras do jogo de linguagem científico (bem como na forma de vida que o dá sentido) (ADAMOGLU DE OLIVEIRA, 2013), o resgate da sensibilidade viabilizadora da noção de responsabilidade de uma prática de pesquisa real, histórica e contextualizada do pesquisador com seu campo social demanda um certo 'desatar dos nós' dessa linguagem introjetada no pesquisador pela sua própria formação, no mais terapêutico sentido que uma pragmática da linguagem pode oferecer - como já sinalizara Wittgenstein $(2009, \S 2)$.

Dessa maneira, desejo concluir indicando que a noção de habitus linguístico oferecida por Bourdieu (1996) fornece uma condição ampliada para a discussão da cientificidade e da validade epistêmica e metodológica demandadas na prática da pesquisa, ao passo que confere maior saliência ao papel e à importância do ato de se praticar uma linguagem - bem como à importância da compreensão sobre os jogos de linguagem da Ciência em seus domínios, disciplinas, cisões e terrenos tensionados - na tessitura constitutiva das relações sociais desse campo. Trata-se de considerar todo o conjunto linguístico estruturante do fazer social que acompanha o fazer político da prática da pesquisa científica, em foco nesta Mesa. Antes do método legitimado e reproduzido no fazer científico, e da devoção pura ao logicismo e a tecnicidade do método em si, cabe-nos atentar para o habitus linguístico engendrado - em cada um de nós - nas e pelas comunidades linguísticas as quais pesquisadores aderem e fazem parte, de modo a compreendermos o que de fato ancora a relação entre os processos de legitimação daquele (o método), suas características, e sua aceitação e reprodução (em graus variáveis de reflexividade) por nós (os pesquisadores).

\section{Referências}

ADAMOGLU DE OLIVEIRA, S. Um olhar pragmático da linguagem cotidiana sobre o ato de praticar a estratégia a partir da noção de "jogos de linguagem": uma análise wittgensteiniana como contribuição teórica e 
metodológica para os campos dos Estudos Organizacionais e da Estratégia Organizacional. 2013. 236f. Tese (Doutorado em Administração) Universidade Federal do Paraná, Curitiba, Paraná, 2013. Disponível em: < http://acervodigital.ufpr.br/handle/1884/30392>. Acesso em: 12 nov. 2013.

BOURDIEU, P. A economia das trocas linguísticas: o que falar quer dizer. São Paulo: Editora da Universidade de São Paulo, 1996.

BOURDIEU, P. Os usos sociais da ciência: por uma sociologia clínica do campo científico. São Paulo: Editora UNESP, 2004.

ENCREVÉ, P. A palavra e seu preço. In: ENCREVÉ, P.; LAGRAVE, R-M. (Coord.). Trabalhar com Bourdieu. Rio de Janeiro: Bertrand Brasil, 2005, p. 261-270.

HABERMAS, J. Técnica e ciência como ideologia. 1. ed. São Paulo: Editora UNESP, 2014.

HANKS, W. F. Pierre Bourdieu e as práticas de linguagem. In: HANKS, W. F. / BENTES, A. C.; REZENDE, R. C.; MACHADO, M. A. R. (Org.). Língua como prática social: das relações entre língua, cultura e sociedade a partir de Bourdieu e Bakthin. São Paulo: Cortez, 2008, p. 33-63.

HARRIS, R. The semantics of science. London: Continuum International Publishing Group, 2005.

MERTON, R. K. On social structure and science - edited and with an introduction by Piotr Sztompka. Chicago: The University of Chicago Press, 1996.

WITTGENSTEIN, L. Investigações filosóficas. 6. ed. Petrópolis: Vozes, 2009.

Submetido em: 24/03/2017

Aprovado em: 20/04/2017

Revista Brasileira de Estudos Organizacionais - v. 3. n. 2, p. 210-215, dez.2016, eISSN: 2447-4851

Doi 10.21583/2447-4851.rbeo.2016.v3n2.88

Sociedade Brasileira de Estudos Organizacionais 